\title{
An Efficient Algorithm for Unconstrained Optimization
}

\author{
Sergio Gerardo de-los-Cobos-Silva, ${ }^{1}$ Miguel Ángel Gutiérrez-Andrade, ${ }^{1}$ \\ Roman Anselmo Mora-Gutiérrez, ${ }^{2}$ Pedro Lara-Velázquez, ${ }^{1}$ \\ Eric Alfredo Rincón-García, ${ }^{2}$ and Antonin Ponsich ${ }^{2}$ \\ ${ }^{1}$ Departamento de Ingeniería Eléctrica, Universidad Autónoma Metropolitana-Iztapalapa, Avenida San Rafael Atlixco 186, \\ Colonia Vicentina, Delegación Iztapalapa, 09340 México, DF, Mexico \\ ${ }^{2}$ Departamento de Sistemas, Universidad Autónoma Metropolitana-Azcapotzalco, Avenida San Pablo 180, \\ Colonia Reynosa Tamaulipas, 02200 México, DF, Mexico
}

Correspondence should be addressed to Eric Alfredo Rincón-García; rigaeral@correo.azc.uam.mx

Received 29 April 2015; Revised 4 August 2015; Accepted 6 August 2015

Academic Editor: Peide Liu

Copyright (C) 2015 Sergio Gerardo de-los-Cobos-Silva et al. This is an open access article distributed under the Creative Commons Attribution License, which permits unrestricted use, distribution, and reproduction in any medium, provided the original work is properly cited.

This paper presents an original and efficient PSO algorithm, which is divided into three phases: (1) stabilization, (2) breadth-first search, and (3) depth-first search. The proposed algorithm, called PSO-3P, was tested with 47 benchmark continuous unconstrained optimization problems, on a total of 82 instances. The numerical results show that the proposed algorithm is able to reach the global optimum. This work mainly focuses on unconstrained optimization problems from 2 to 1,000 variables.

\section{Introduction}

In general, an optimization problem can be defined as

$$
\min _{x \in X} h(x) .
$$

In recent decades several heuristic optimization methods have been developed. These techniques are able to find solutions close to the optimum, where exact or analytic methods cannot produce optimal solutions within reasonable computation time. This is especially true when a global optimum is surrounded by many local optima, a situation known as deep valleys or black holes.

Different heuristic solution methods have been developed, among others, Tabu Search (TS) [1], Simulated Annealing (SA) [2], genetic algorithms (GA) [3], Scatter Search (SS) [4], and particle swarm optimization (PSO) [5].

In particular, for PSO there are so many different versions, a treaty on its taxonomy can be found in [6]. For a review of its variants, see [7]. With respect to unconstrained optimization, [8] proposed a modified algorithm to ensure the rational flight of every particle's dimensional component; two parameters of fitness function evaluation, particle-distributiondegree, and particle-dimension-distance were introduced in order to avoid premature convergence. Reference [9] proposed a two-layer PSO (TLPSO) to increase the diversity of the particles so that the drawback of getting trapped in a local optimum was avoided. Reference [10] introduced a hybrid approach combining particle swarm optimization with genetic algorithm. Reference [11] presented the particle swarm optimization with flexible swarm; the algorithm was tested over 14 benchmark functions for 300,000 iterations for each function. Reference [12] presented two hybrids, a realcoded genetic algorithm-based PSO (RGA-PSO) method, and an artificial immune algorithm-based PSO (AIA-PSO) method. These algorithms were tested over 14 benchmark functions, with 20,000 objective function evaluations of the internal PSO approach for a problem with $N \leq 3$ decision variables and 60,000 objective function evaluations of the internal PSO approach for a problem with $5 \leq N \leq 30$. Reference [13] proposed IRPEO, an improved real-coded population-based EO (extremal optimization) method, that was compared with PSO and PSO-EO; the algorithms were 


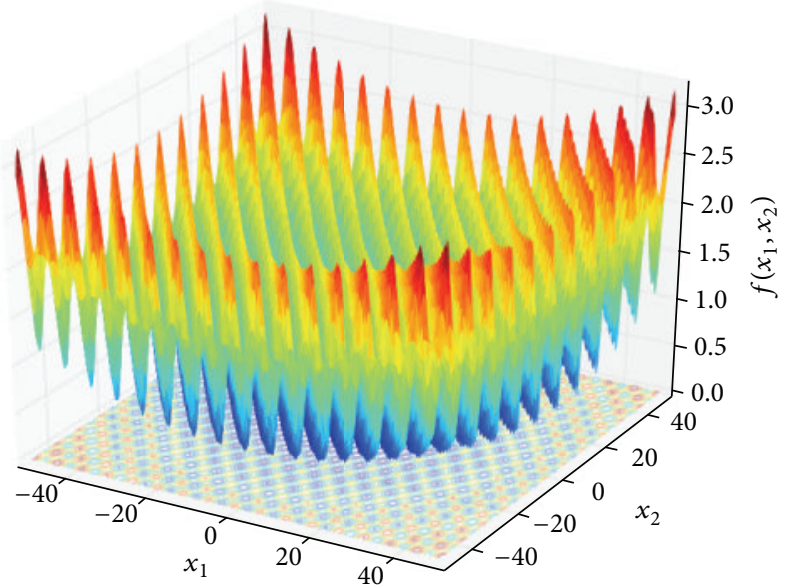

(a) Griewank function ([18] hardness 6.08)

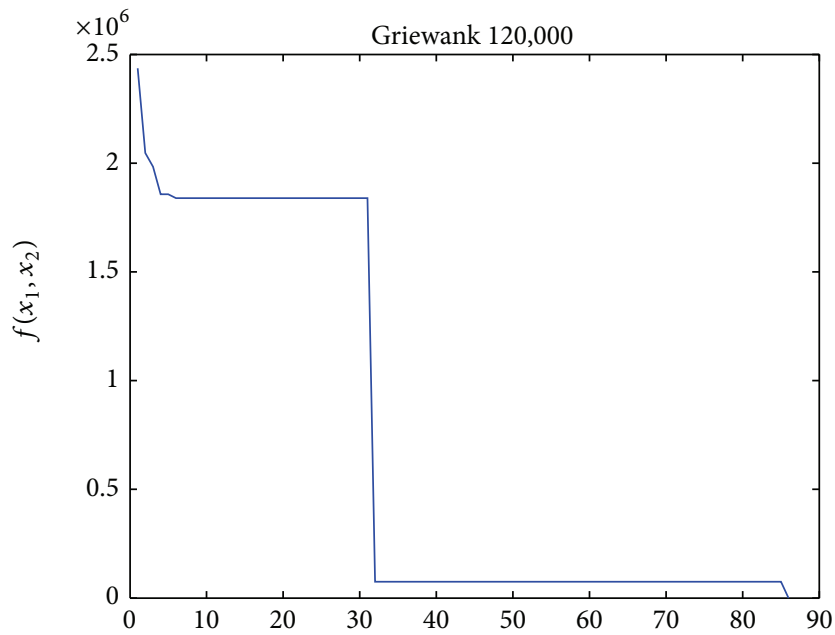

(b) Convergence with PSO-3P for Griewank function (dimension = $120,000)$

FIGURE 1: Griewank function.

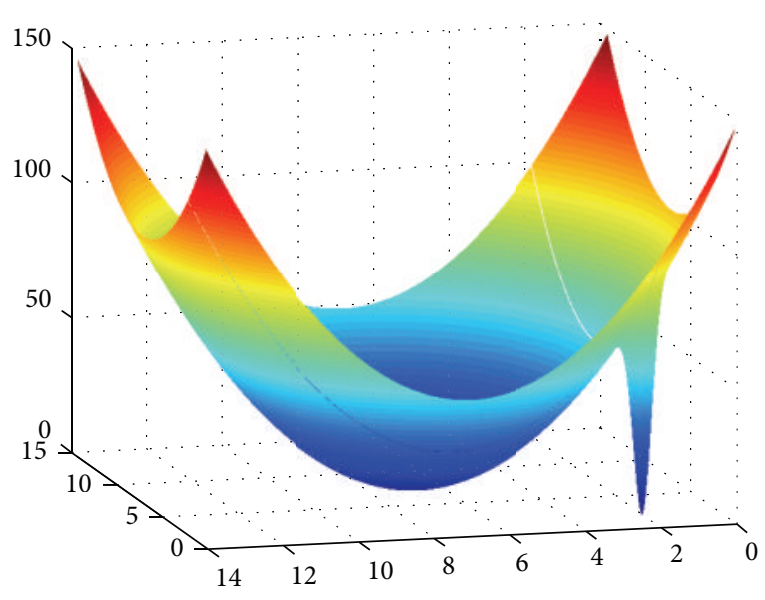

(a) Damavandi function $\left(0.25^{*}\right)$

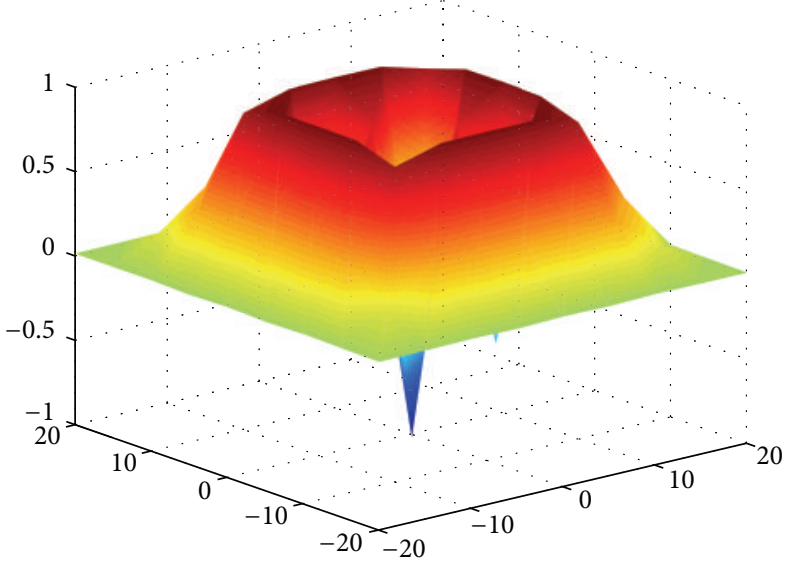

(c) XinSheYang03 function $\left(1.08^{*}\right)$

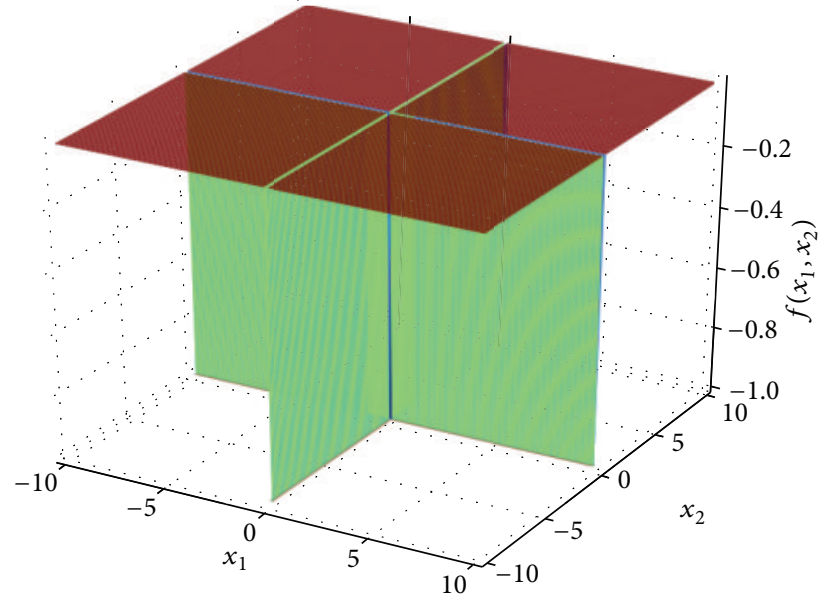

(b) CrossLegTable function $\left(0.83^{*}\right)$

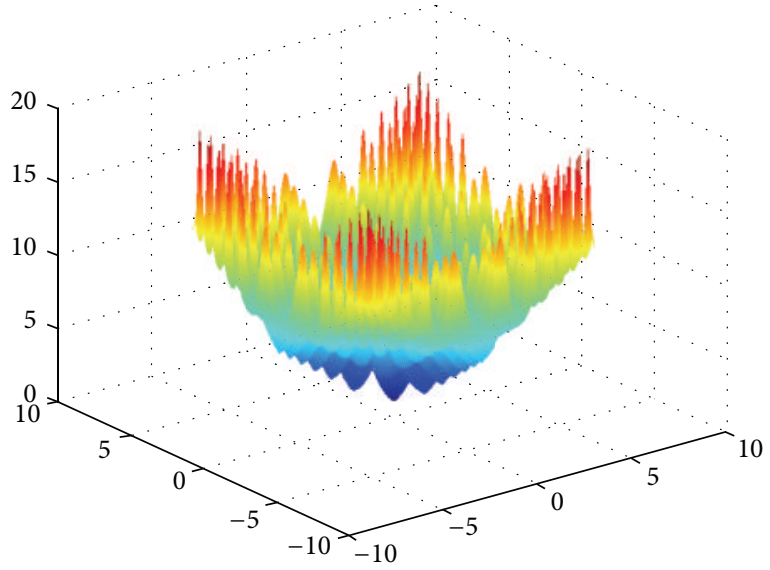

(d) XinSheYang02 function $\left(31.33^{*}\right.$ )

FIGURE 2: Different functions and their ${ }^{*}$ hardness [18]. 
TABLE 1: Time and efficiency.

\begin{tabular}{|c|c|c|c|c|c|}
\hline & Function(dimension) & Part. & Mean Eff. & Time (sec) & Mean Iter. \\
\hline 1 & Ackley(10) & 60 & 0.994679 & 6.99 & 424.63 \\
\hline 2 & Ackley(120) & 3 & 1.000000 & 1.46 & 322.08 \\
\hline 3 & $\operatorname{Ackley}(2)$ & 24 & 0.998171 & 0.70 & 58.58 \\
\hline 4 & $\operatorname{Ackley}(30)$ & 12 & 1.000000 & 1.39 & 185.25 \\
\hline 5 & Ackley(6) & 36 & 0.998272 & 2.37 & 227.00 \\
\hline 6 & Beale(2) & 60 & 1.000000 & 0.58 & 22.88 \\
\hline 7 & Bohachevsky 1(2) & 240 & 1.000000 & 4.86 & 21.88 \\
\hline 8 & Bohachevsky 2(2) & 240 & 1.000000 & 4.71 & 20.42 \\
\hline 9 & Booth(2) & 240 & 1.000000 & 5.01 & 18.71 \\
\hline 10 & $\operatorname{Branin}(2)$ & 24 & 0.999960 & 0.50 & 58.46 \\
\hline 11 & Bukin6(2) & 12 & 0.875325 & 2.96 & 499.00 \\
\hline 12 & Colville(4) & 3 & 0.791743 & 2.56 & 749.00 \\
\hline 13 & CrossLegTable $(2)^{* *}(0.83)$ & 60 & 0.833426 & 8.07 & 198.42 \\
\hline 14 & Cross-in-Tray(2) & 3 & 0.999908 & 1.61 & 422.38 \\
\hline 15 & Damavandi $(2){ }^{* *}(0.25)$ & 60 & 0.989719 & 12.42 & 490.25 \\
\hline 16 & DevillierGlasser02(5) ${ }^{* *}(0.00)$ & 12 & 1.000000 & 2.60 & 499.00 \\
\hline 17 & Drop Wave(2) & 3 & 1.000000 & 0.78 & 223.54 \\
\hline 18 & Easom(2) & 24 & 1.000000 & 0.27 & 17.54 \\
\hline 19 & Eggholder(2) & 240 & 0.980028 & 32.87 & 499.00 \\
\hline 20 & Goldstein-Price(2) & 60 & 1.000000 & 0.52 & 19.00 \\
\hline 21 & Griewank(10) & 12 & 1.000000 & 1.23 & 185.50 \\
\hline 22 & Griewank(100) & 24 & 1.000000 & 0.73 & 87.00 \\
\hline 23 & Griewank(2) & 24 & 1.000000 & 1.53 & 191.04 \\
\hline 24 & Griewank(30) & 12 & 1.000000 & 1.38 & 218.21 \\
\hline 25 & Griewank(6) & 36 & 1.000000 & 1.37 & 86.13 \\
\hline 26 & Hartmann(3) & 24 & 0.999999 & 0.57 & 43.50 \\
\hline 27 & Hartmann(6) & 12 & 0.986473 & 2.21 & 399.50 \\
\hline 28 & Holder Table(2) & 24 & 0.999863 & 1.79 & 201.79 \\
\hline 29 & Levy(12) & 3 & 0.985893 & 1.75 & 499.00 \\
\hline 30 & Levy(120) & 24 & 0.999918 & 6.07 & 499.00 \\
\hline 31 & $\operatorname{Levy}(2)$ & 240 & 1.000000 & 5.53 & 17.92 \\
\hline 32 & Levy13(2) & 240 & 1.000000 & 4.60 & 20.25 \\
\hline 33 & Matyas(2) & 240 & 1.000000 & 4.92 & 17.92 \\
\hline 34 & McCormick(2) & 12 & 0.999947 & 3.32 & 499.00 \\
\hline 35 & Michalewicz(2) & 24 & 0.999998 & 0.38 & 39.33 \\
\hline 36 & Michalewicz(5) & 120 & 0.957199 & 13.90 & 407.80 \\
\hline 37 & Powell(10) & 12 & 1.000000 & 2.24 & 385.54 \\
\hline 38 & Powell(12) & 3 & 1.000000 & 1.52 & 466.29 \\
\hline 39 & Powell(120) & 3 & 1.000000 & 1.62 & 489.13 \\
\hline 40 & Powell(2) & 3 & 1.000000 & 1.28 & 499.00 \\
\hline 41 & Power Sum(4) & 240 & 0.994381 & 100.60 & 477.00 \\
\hline 42 & Rastrigin(10) & 24 & 1.000000 & 1.91 & 252.75 \\
\hline
\end{tabular}

** The overall success of different global optimizers according to Gavana [18].

tested over 12 benchmark functions with 10,000-50,000 iterations for problems with dimension $N=10,30$.

In this paper, we present a PSO-3P [14] based algorithm that uses three phases to guide the search through the solution space. In order to test the performance of PSO-3P, it was applied to 47 benchmark continuous unconstrained optimization problems, over a total of 82 instances. After some computational experiments, we observed that PSO-3P is able to escape from suboptimal entrapments.

In particular, the proposed PSO-3P algorithm was able to reach the global optimum for the Griewank function with 120,000 variables, $x_{i} \in[-600,600]$, in 40 seconds in average, 
TABle 2: Time and efficiency.

\begin{tabular}{|c|c|c|c|c|c|}
\hline & Function(dimension) & Part. & Mean Eff. & Time (sec) & Mean Iter. \\
\hline 43 & Rastrigin(100) & 24 & 1.000000 & 2.07 & 262.50 \\
\hline 44 & Rastrigin(3) & 24 & 0.999920 & 5.56 & 542.21 \\
\hline 45 & Rastrigin(30) & 24 & 1.000000 & 2.03 & 265.33 \\
\hline 46 & Rastrigin(6) & 24 & 1.000000 & 1.84 & 245.08 \\
\hline 47 & Rosenbrock(10) & 24 & 1.000000 & 1.64 & 218.04 \\
\hline 48 & Rosenbrock(100) & 24 & 0.966926 & 2.32 & 674.92 \\
\hline 49 & Rosenbrock(2) & 24 & 1.000000 & 0.24 & 26.33 \\
\hline 50 & Rosenbrock(30) & 12 & 0.999706 & 1.68 & 258.35 \\
\hline 51 & Rosenbrock(6) & 24 & 1.000000 & 2.77 & 241.67 \\
\hline 52 & Rotated Hyper-Ellipsoid(12) & 3 & 1.000000 & 1.21 & 361.04 \\
\hline 53 & Rotated Hyper-Ellipsoid(120) & 3 & 1.000000 & 1.25 & 323.78 \\
\hline 54 & Rotated Hyper-Ellipsoid(2) & 240 & 1.000000 & 4.66 & 20.33 \\
\hline 55 & Schaffer2(2) & 240 & 1.000000 & 4.68 & 21.17 \\
\hline 56 & Schwefel 26(100) & 120 & 0.924108 & 16.26 & 490.50 \\
\hline 57 & Schwefel 26(2) & 120 & 0.994103 & 15.93 & 499.00 \\
\hline 58 & Shekel(4) & 60 & 0.999580 & 5.36 & 322.50 \\
\hline 59 & Shubert(2) & 240 & 1.000000 & 4.45 & 14.08 \\
\hline 60 & Six-Hump Camel(2) & 12 & 0.999974 & 2.73 & 499.00 \\
\hline 61 & Sphere(12) & 3 & 1.000000 & 1.02 & 303.42 \\
\hline 62 & Sphere(120) & 3 & 1.000000 & 1.08 & 315.79 \\
\hline 63 & Sphere(2) & 240 & 1.000000 & 4.58 & 16.96 \\
\hline 64 & Styblinski-Tang(12) & 3 & 0.999900 & 1.81 & 499.00 \\
\hline 65 & Styblinski-Tang(120) & 3 & 0.999884 & 1.96 & 499.00 \\
\hline 66 & Styblinski-Tang(2) & 24 & 0.999905 & 0.24 & 25.17 \\
\hline 67 & Sum of Different Powers(12) & 3 & 1.000000 & 0.73 & 213.79 \\
\hline 68 & Sum of Different Powers(120) & 3 & 1.000000 & 0.98 & 277.65 \\
\hline 69 & Sum of Different Powers(2) & 240 & 1.000000 & 15.37 & 193.75 \\
\hline 70 & Sum Squares(12) & 3 & 1.000000 & 0.91 & 262.38 \\
\hline 71 & Sum Squares(120) & 3 & 1.000000 & 1.03 & 297.25 \\
\hline 72 & Sum Squares(2) & 24 & 1.000000 & 0.16 & 15.38 \\
\hline 73 & Three-Hump Camel(2) & 240 & 1.000000 & 4.54 & 17.29 \\
\hline 74 & $\operatorname{Trid}(10)$ & 48 & 0.993918 & 10.11 & 499.00 \\
\hline 75 & $\operatorname{Trid}(6)$ & 240 & 0.996842 & 32.12 & 499.00 \\
\hline 76 & Xin She Yang02(12) & 48 & 1.000000 & 5.18 & 157.92 \\
\hline 77 & Xin She Yang02(120) & 48 & 1.000000 & 6.86 & 254.54 \\
\hline 78 & Xin She Yang02(2) & 48 & 1.000000 & 4.83 & 148.83 \\
\hline 79 & Xin She Yang03(2) ${ }^{* *}(1.08)$ & 3 & 1.000000 & 0.55 & 160.33 \\
\hline 80 & Zakharov(12) & 3 & 1.000000 & 1.15 & 357.21 \\
\hline 81 & Zakharov(120) & 3 & 0.999958 & 1.35 & 430.13 \\
\hline 82 & Zakharov(2) & 240 & 1.000000 & 4.55 & 17.75 \\
\hline
\end{tabular}

** The overall success of different global optimizers according to Gavana [18].

using only 3 particles and 90 iterations (see Figures 1(a) and 1(b)). This instance was solved using Matlab and run on a Notebook with an Intel Atom N280 processor at $1.66 \mathrm{Ghz}$.

The remainder of this paper is divided as follows: a background of PSO is presented in the following section. The general guidelines of PSO-3P are described in Section 3. Numerical examples are provided in Section 4. Finally, Section 5 includes conclusions and future research.

\section{PSO}

The particle swarm optimization is a metaheuristic based on swarm intelligence and has its roots in artificial life, social psychology, engineering, and computer science. PSO differs from evolutionary computation (c.f. [15]) because the population members or agents, also called particles, are "flying" through the problem hyperspace. 
TABLE 3: Results with 3 and 6 particles.

\begin{tabular}{|c|c|c|c|c|c|c|}
\hline & Function(Dim.) & Part. & Time (sec) & Perc. & Mean Iter. & EOF \\
\hline 1 & Ackley(10) & 3 & 1.4 & 20.8 & 455.6 & 1366.8 \\
\hline 2 & Ackley(120) & 3 & 1.5 & 62.5 & 385.5 & 1156.5 \\
\hline 3 & $\operatorname{Ackley}(2)$ & 3 & 1.2 & 37.5 & 379.2 & 1137.6 \\
\hline 4 & Bohachevsky 1(2) & 3 & 0.8 & 100 & 236.9 & 710.7 \\
\hline 5 & Bohachevsky 2(2) & 3 & 0.8 & 100 & 241.8 & 725.4 \\
\hline 6 & Bohachevsky 3(2) & 3 & 0.8 & 100 & 247.5 & 742.5 \\
\hline 7 & $\operatorname{Branin}(2)$ & 6 & 3.4 & 4.2 & 484.4 & 2906.4 \\
\hline 8 & Colville(4) & 3 & 1.6 & 4.2 & 485 & 1455 \\
\hline 9 & CrossLegTable(2) (0.83) & 3 & 0.8 & 75 & 223.6 & 670.8 \\
\hline 10 & Cross-in-Tray(2) & 3 & 1.7 & 16.7 & 460 & 1380 \\
\hline 11 & DevillierGlasser02(5) (0.00) & 3 & 0.6 & 100 & 151.9 & 455.7 \\
\hline 12 & Drop Wave(2) & 3 & 1.2 & 100 & 142 & 426 \\
\hline 13 & Easom(2) & 3 & 1.5 & 8.3 & 466.5 & 1399.5 \\
\hline 14 & Goldstein-Price(2) & 3 & 1.6 & 4.2 & 483 & 1449 \\
\hline 15 & Griewank(10) & 3 & 0.3 & 100 & 88.5 & 265.5 \\
\hline 16 & Griewank(100) & 3 & 0.4 & 100 & 88.3 & 264.9 \\
\hline 17 & Griewank(2) & 3 & 0.7 & 100 & 209.5 & 628.5 \\
\hline 18 & Griewank(30) & 3 & 0.9 & 75 & 193.7 & 581.1 \\
\hline 19 & Griewank(6) & 3 & 0.3 & 100 & 88.2 & 264.6 \\
\hline 20 & $\operatorname{Hartmann}(3)$ & 3 & 1.8 & 4.2 & 485.5 & 1456.5 \\
\hline 21 & Holder Table(2) & 6 & 2.6 & 4.2 & 478.9 & 2873.4 \\
\hline 22 & Levy(12) & 6 & 2.4 & 8.3 & 475.5 & 2853 \\
\hline 23 & Levy(120) & 6 & 2.9 & 12.5 & 474.8 & 2848.8 \\
\hline 24 & $\operatorname{Levy}(2)$ & 6 & 2.3 & 8.3 & 465.3 & 2791.8 \\
\hline 25 & Levy13(2) & 6 & 2.4 & 4.2 & 484.3 & 2905.8 \\
\hline 26 & Matyas(2) & 3 & 0.8 & 100 & 237.6 & 712.8 \\
\hline 27 & Michalewicz(2) & 3 & 2 & 54.2 & 367 & 1101 \\
\hline 28 & Powell(10) & 3 & 1.7 & 4.2 & 497.3 & 1491.9 \\
\hline 29 & Powell(12) & 3 & 0.6 & 95.8 & 200.3 & 600.9 \\
\hline 30 & Powell(120) & 3 & 0.7 & 100 & 207.6 & 622.8 \\
\hline 31 & Powell(2) & 3 & 0.7 & 95.8 & 261.5 & 784.5 \\
\hline 32 & Rastrigin(10) & 3 & 0.8 & 100 & 261.8 & 785.4 \\
\hline
\end{tabular}

PSO is an adaptive method that uses agents or particles moving through the search space using the principles of evaluation, comparison, and imitation [15].

PSO is based on the use of a set of particles or agents that correspond to states of an optimization problem, where each particle moves across the solution space in search of an optimal position or at least a good solution. In PSO, agents communicate with each other, and the agent with the best position (measured according to an objective function) influences the others by attracting them towards itself.

The population is started by assigning an initial random position and speed for each element. At each iteration, the velocity of each particle is randomly accelerated towards its best position (where the value of the fitness function or objective function improves) and also considering the best positions of their neighbors.
To solve a problem, PSO uses a dynamic management of particles; this approach allows breaking cycles and diversifying the search. In this work, $r$-particle swarm is represented at time $t$ under the form

$$
\theta_{1 t}, \theta_{2 t}, \ldots, \theta_{r t}
$$

with $\theta_{j, t} \in D, j=1,2, \ldots, r$; then a movement of the swarm is defined according to

$$
\theta_{j, t+1}=\theta_{j, t}+V_{j, t+1},
$$

where the velocity $V_{j, t+1}$ is given in

$$
\begin{aligned}
V_{j, t+1}= & \alpha V_{j, t}+\operatorname{rand}\left(0, \varphi_{1}\right)\left[\theta_{j, t}^{\prime}-\theta_{j, t}\right] \\
& +\operatorname{rand}\left(0, \varphi_{2}\right)\left[\theta_{g, t}^{\prime}-\theta_{j, t}\right],
\end{aligned}
$$


TABLE 4: Results considering 3 and 6 particles.

\begin{tabular}{|c|c|c|c|c|c|c|}
\hline & Function(dim) & Part. & Time $(\mathrm{sec})$ & Perc. & Mean Iter. & EOF \\
\hline 33 & Rastrigin(100) & 3 & 1.3 & 100 & 289.8 & 869.4 \\
\hline 34 & Rastrigin(3) & 6 & 2.8 & 8.3 & 487.1 & 2922.6 \\
\hline 35 & Rastrigin(30) & 3 & 1.3 & 95.8 & 291.4 & 874.2 \\
\hline 36 & Rastrigin(6) & 6 & 1.8 & 100 & 272.5 & 1635 \\
\hline 37 & Rosenbrock(10) & 3 & 1.1 & 66.7 & 331 & 993 \\
\hline 38 & Rosenbrock(2) & 3 & 0.5 & 79.2 & 140.3 & 420.9 \\
\hline 39 & Rosenbrock(30) & 3 & 1.2 & 50 & 379.2 & 1137.6 \\
\hline 40 & Rosenbrock(6) & 3 & 0.3 & 100 & 87.5 & 262.5 \\
\hline 41 & Rotated Hyper-Ellipsoid(12) & 3 & 0.6 & 100 & 179 & 537 \\
\hline 42 & Rotated Hyper-Ellipsoid(120) & 3 & 0.9 & 95.8 & 221.5 & 664.5 \\
\hline 43 & Rotated Hyper-Ellipsoid(2) & 3 & 0.8 & 100 & 231 & 693 \\
\hline 44 & Schaffer2(2) & 3 & 0.7 & 100 & 221 & 663 \\
\hline 45 & Shekel(4) & 3 & 0.8 & 100 & 216.5 & 649.5 \\
\hline 46 & Six-Hump Camel(2) & 3 & 1.7 & 8.3 & 468 & 1404 \\
\hline 47 & Sphere(12) & 3 & 0.5 & 95.8 & 162.6 & 487.8 \\
\hline 48 & Sphere(120) & 3 & 0.5 & 95.8 & 166.9 & 500.7 \\
\hline 49 & Sphere(2) & 3 & 0.7 & 100 & 217.4 & 652.2 \\
\hline 50 & Styblinski-Tang(2) & 3 & 1.5 & 20.8 & 416.9 & 1250.7 \\
\hline 51 & Sum of Different Powers(12) & 3 & 0.5 & 95.8 & 144.1 & 432.3 \\
\hline 52 & Sum of Different Powers(120) & 3 & 0.5 & 100 & 128.3 & 384.9 \\
\hline 53 & Sum of Different Powers(2) & 3 & 0.9 & 100 & 270.2 & 810.6 \\
\hline 54 & Sum Squares(12) & 3 & 0.5 & 100 & 148.9 & 446.7 \\
\hline 55 & Sum Squares(120) & 3 & 0.6 & 100 & 186.8 & 560.4 \\
\hline 56 & Sum Squares(2) & 3 & 0.7 & 100 & 222.7 & 668.1 \\
\hline 57 & Three-Hump Camel(2) & 3 & 0.7 & 100 & 209.8 & 629.4 \\
\hline 58 & Xin She Yang02(12) & 3 & 1.2 & 95.8 & 351 & 1053 \\
\hline 59 & Xin She Yang02(120) & 3 & 2.8 & 25 & 451.1 & 1353.3 \\
\hline 60 & Xin She Yang02(2) & 3 & 0.6 & 95.8 & 170.1 & 510.3 \\
\hline 61 & Xin She Yang03(2) (1.08) & 3 & 0.5 & 100 & 155.3 & 465.9 \\
\hline 62 & Zakharov(12) & 3 & 0.6 & 95.8 & 178.3 & 534.9 \\
\hline 63 & Zakharov(120) & 3 & 1.2 & 75 & 373.6 & 1120.8 \\
\hline 64 & Zakharov(2) & 3 & 1.6 & 4.2 & 488.9 & 1466.7 \\
\hline
\end{tabular}

where $D$ is space of feasible solutions, $V_{j, t}$ is speed at time $t$ of the $j$ th particle, $V_{j, t+1}$ is speed at time $t+1$ of the $j$ th particle, $\theta_{j, t}$ is $j$ th particle at time $t, \theta_{g, t}^{\prime}$ is the particle with the best value found so far (i.e., before time $t$ ), $\theta_{j, t}^{\prime}$ is best position found so far by the $j$ th particle (before time $t$ ), $\operatorname{rand}(0, \varphi)$ is random number uniformly distributed over the interval $[0, \varphi]$, and $\alpha$ is inertia weight factor.

The PSO algorithm is described in Algorithm 1.

\section{PSO-3P}

In this section, the main characteristics of the proposed algorithm, called PSO-3P, are described. The PSO-3P is based on a traditional PSO heuristic. However, the position of the particles can be modified using different strategies, which are sequentially applied in three phases of the searching process.

In phase 1, called stabilization, according to the description presented in Section 2, the PSO-3P algorithm generates randomly a set of particles in the solution space. Then, during it $F_{1}$ iterations the position of the particles is modified using (3) and (4). Thus, at the end of this phase the particles are concentrated, or stabilized, in a promising region.

When phase 1 is completed, a breadth-first search strategy, called phase 2 , is incorporated. In this phase, if the global best solution is not improved after $c$ consecutive iterations, a random particle is created and, with a probability bigger than 0.5 , takes the place of one particle randomly selected in the swarm. This process of creation and replacement is repeated $n$ Pop $*$ prop times. However, the particle with the best known position is preserved. Thus, the population is dispersed in the solution space, but it can be attracted to the best region visited so far. This diversification strategy is considered during it $F_{2}$ iterations.

Finally, phase 3 is initialized. During it $F_{3}$ iterations the following depth-first search strategy is applied. If the global best solution is not improved after $c$ consecutive iterations, $n$ Pop $*$ prop particles are randomly created in a neighborhood 
TABLE 5: Ackley problem.

\begin{tabular}{|c|c|c|c|c|c|c|c|c|}
\hline Algorithm & Dim. & M. G/I & P. & EOF & Best & Average & Median & Time (s) \\
\hline PSO-3P & 10 & 500 & 3 & $515^{*}$ & $7.99 E-15$ & $7.56 E-05$ & $7.99 E-15$ & 0.655 \\
\hline PSO-3P & 30 & 500 & 3 & $482^{*}$ & $7.99 E-15$ & $1.40 E-05$ & $7.99 E-15$ & 0.558 \\
\hline ELIPSO [19] & 30 & 100 & 1500 & - & 0.078 & 0.2279 & 0.3169 & - \\
\hline LDWIPSO [19] & 30 & 100 & 1500 & - & 0.0009 & 1.8896 & 2.0099 & - \\
\hline FIWPSO [19] & 30 & 100 & 1500 & - & 1.1552 & 2.6922 & 2.4962 & - \\
\hline CIWPSO [19] & 30 & 100 & 1500 & - & 1.3567 & 2.5694 & 2.4482 & - \\
\hline RIWPSO [19] & 30 & 100 & 1500 & - & 0.9313 & 2.3145 & 2.3584 & - \\
\hline TVACPSO [19] & 30 & 100 & 1500 & - & 1.157 & 2.1255 & 2.221 & - \\
\hline COPSO [19] & 30 & 100 & 1500 & - & 2.1201 & 2.9663 & 2.8098 & - \\
\hline IRPEO [13] & 30 & 50000 & 50 & - & $1.15 E-04$ & $2.91 E-04$ & - & - \\
\hline pPSA [20] & 30 & 2000 & 30 & - & $1.52 E-03$ & $1.19 E+00$ & $9.31 E-01$ & - \\
\hline PSO [21] & 30 & 1000 & - & - & $2.58 E+00$ & - & - & - \\
\hline SFLA [21] & 30 & 1000 & - & - & $2.40 E+00$ & - & - & 1.83 \\
\hline MSFLA [21] & 30 & 1000 & - & 490000 & $2.10 E-01$ & - & - & 6.25 \\
\hline MSFLA-EO [21] & 30 & 1000 & - & 2900000 & $0.00 E+00$ & - & - & - \\
\hline PSO-EO [22] & 30 & 10000 & 30 & - & $9.50 E-04$ & $9.88 E-04$ & - & 0.26 \\
\hline LX-PM [23] & 30 & 5000 & 300 & 86661 & - & $1.01 E-10$ & - & 1.625 \\
\hline LX-MPTM [23] & 30 & 5000 & 300 & 116731 & - & $2.18 E-07$ & - & 2.243 \\
\hline LX-NUM [23] & 30 & 5000 & 300 & 130041 & - & $6.66 E-07$ & - & 2.473 \\
\hline HX-PM [23] & 30 & 5000 & 300 & 178301 & - & $1.01 E-10$ & - & 2.8 \\
\hline HX-MPTM [23] & 30 & 5000 & 300 & 196401 & - & $3.17 E-04$ & - & 3.565 \\
\hline HX-NUM [23] & 30 & 5000 & 300 & 232901 & - & $1.28 E-03$ & - & 4.134 \\
\hline $\mathrm{ADM}[24]$ & 30 & $2348^{*}$ & - & - & - & $3.28 E-01$ & - & 91.25 \\
\hline RM [24] & 30 & $29824^{*}$ & - & - & - & $1.42 E-03$ & - & 3389.03 \\
\hline PLM [24] & 30 & $30000^{*}$ & - & - & - & $3.47 E-04$ & - & 3053.57 \\
\hline NUM [24] & 30 & $29590^{*}$ & - & - & - & $5.91 E-04$ & - & 874.63 \\
\hline MNUM [24] & 30 & $17290^{*}$ & - & - & - & $1.82 E-01$ & - & 453.05 \\
\hline PM [24] & 30 & $25554^{*}$ & - & - & - & $4.46 E-01$ & - & 933.23 \\
\hline PSO-3P & 50 & 500 & 3 & $511^{*}$ & $7.99 E-15$ & $9.60 E-05$ & $7.99 E-15$ & 0.632 \\
\hline CSA [25] & 50 & 2000 & - & 4000 & - & $5.00 E-01$ & - & - \\
\hline ACSA [25] & 50 & 2000 & - & 2500 & - & $8.71 E-06$ & - & - \\
\hline PSO-3P & 100 & 500 & 3 & $952^{*}$ & $8.88 E-16$ & $8.88 E-16$ & $8.88 E-16$ & 1.040 \\
\hline ELPSO [19] & 100 & 100 & 5000 & - & 0.0475 & 0.2255 & 0.1589 & - \\
\hline CPSO [19] & 100 & - & - & - & 3.6588 & 4.7431 & 4.6822 & - \\
\hline HS [19] & 100 & - & - & - & 12.876 & 13.3999 & 13.5271 & - \\
\hline GA [19] & 100 & - & - & - & 10.2225 & 10.7037 & 10.5791 & - \\
\hline FSO [19] & 100 & - & - & - & 0.0256 & 0.0275 & 0.0273 & - \\
\hline GSA [19] & 100 & - & - & - & 1.7456 & 11.4327 & 6.0956 & - \\
\hline BSOA [19] & 100 & - & - & - & 6.4311 & 8.0122 & 7.9955 & - \\
\hline ABC [19] & 100 & - & - & - & 17.1928 & 17.5914 & 17.5324 & - \\
\hline PSO-3P & 120 & 500 & 3 & $947^{*}$ & $7.99 E-15$ & $6.22 E-07$ & $7.99 E-15$ & 1.638 \\
\hline PSO-3P & 1000 & 500 & 3 & $470^{*}$ & $7.99 E-15$ & $4.52 E-05$ & $7.99 E-15$ & 0.555 \\
\hline
\end{tabular}

${ }^{*}$ Average.

of the best known solution and take the place of equal number of randomly selected particles in the swarm. Thus, phase 3 includes an intensification process in a promising region.

The main steps of the PSO-3P algorithm are described in Algorithm 2.

\section{Computational Results}

In order to evaluate the performance of the proposed PSO$3 \mathrm{P}$ algorithm, 47 unconstrained optimization problems taken from [16-18] were used. An in-depth study for multiobjective optimization, and constrained optimization, will be presented in a future work.

These problems include functions that are scalable to arbitrary dimensions such as Ackley, Rastrigin, Rosenbrock, Sphere, and Zakharov. So far, these problems have been widely used as benchmarks for study with different methods by many researchers; see [13, 19-25]. Also functions that are especially difficult to solve were included; for example, according to [18], the overall success of different global 


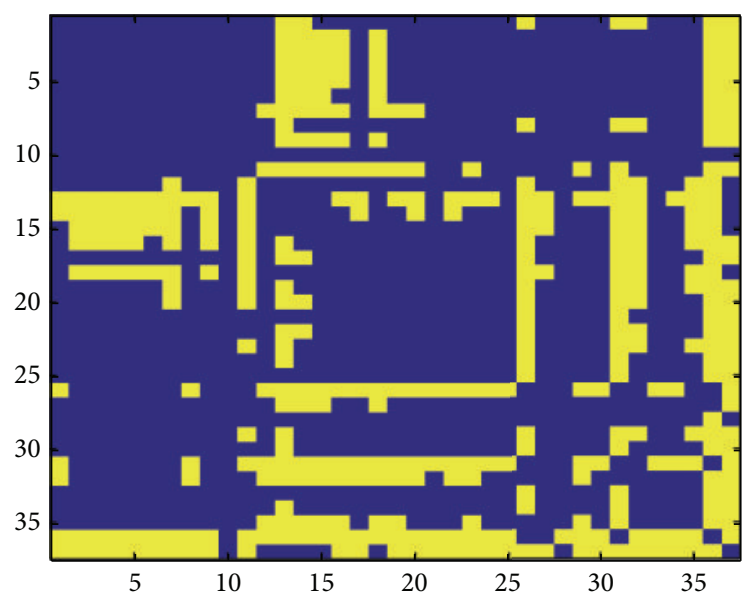

FIGURE 3: Wilcoxon sum rank test, where ELIPSO is represented by 1 [19], LDWIPSO is represented by 2 [19], FIWPSO is represented by 3 [19], CIWPSO is represented by 4 [19], RIWPSO is represented by 5 [19], TVACPSO is represented by 6 [19], COPSO is represented by 7 [19], IRPEO is represented by 8 [13], pPSA is represented by 9 [20], PSO is represented by 10 [21], SFLA is represented by 11 [21], MSFLA is represented by 12 [21], MSFLA-EO is represented by 13 [21], PSO$\mathrm{EO}$ is represented by 14 [22], LX-PM is represented by 15 [23], LXMPTM is represented by 16 [23], LX-NUM is represented by 17 [23], HX-PM is represented by 18 [23], HX-MPTM is represented by 19 [23], HX-NUM is represented by 20 [23], ADM is represented by 21 [24], RM is represented by 22 [24], PLM is represented by 23 [24], NUM is represented by 24 [24], MNUM is represented by 25 [24], PM is represented by 26 [24], CSA is represented by 27 [25], ACSA is represented by 28 [25], ELPSO is represented by 29 [19], CPSO is represented by 30 [19], HS is represented by 31 [19], GA is represented by 32 [19], FSO is represented by 33 [19], GSA is represented by 34 [19], BSOA is represented by 35 [19], and ABC is represented by 36 [19].

optimizers on DeVilliersGlasser02, Damavandi, CrossLegTable, XinSheYang03, Griewank, and XinSheYang02 was $0 \%$, $0.25 \%, 0.83 \%, 1.08 \%, 6.08 \%$, and $31.33 \%$, respectively; see Figure 2.

In order to evaluate the performance of the algorithm we used the following efficiency measure:

efficiency

$$
= \begin{cases}1-\operatorname{abs}\left(\frac{h(x)-h\left(x^{*}\right)}{h\left(x^{*}\right)}\right) & \text { if } h\left(x^{*}\right) \neq 0 \\ 1-\operatorname{abs}(h(x)) & \text { if } h\left(x^{*}\right)=0,\end{cases}
$$

where $x^{*}$ is the optimum of function $h$ and $x$ is the best solutions found by the algorithm after one run. When the efficiency was greater than 0.999999 , it was rounded to 1 .

The tuning of the operating parameters was realized using a brute-force approach, as described in [26]. Finally,

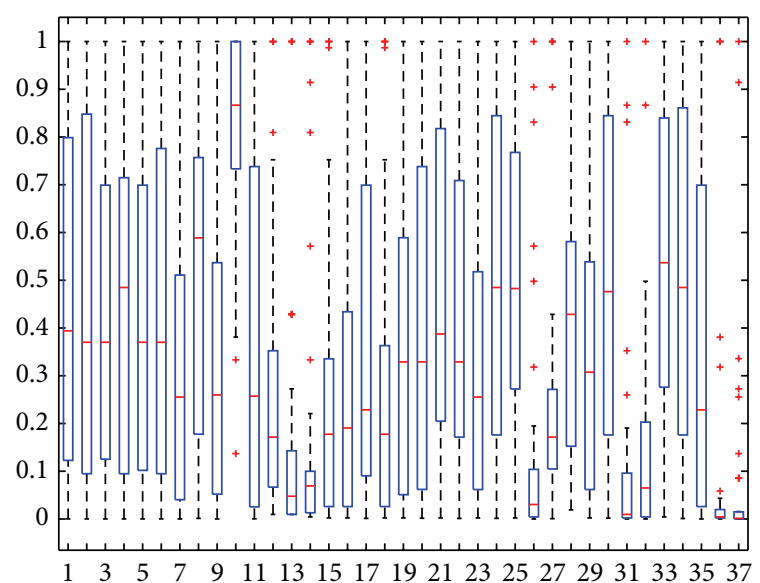

FIgure 4: $P$ values of the Wilcoxon sum rank test, where ELIPSO is represented by 1 [19], LDWIPSO is represented by 2 [19], FIWPSO is represented by 3 [19], CIWPSO is represented by 4 [19], RIWPSO is represented by 5 [19], TVACPSO is represented by 6 [19], COPSO is represented by 7 [19], IRPEO is represented by 8 [13], pPSA is represented by 9 [20], PSO is represented by 10 [21], SFLA is represented by 11 [21], MSFLA is represented by 12 [21], MSFLAEO is represented by 13 [21], PSO-EO is represented by 14 [22], LXPM is represented by 15 [23], LX-MPTM is represented by 16 [23], LX-NUM is represented by 17 [23], HX-PM is represented by 18 [23], HX-MPTM is represented by 19 [23], HX-NUM is represented by 20 [23], ADM is represented by 21 [24], RM is represented by 22 [24], PLM is represented by 23 [24], NUM is represented by 24 [24], MNUM is represented by 25 [24], PM is represented by 26 [24], CSA is represented by 27 [25], ACSA is represented by 28 [25], ELPSO is represented by 29 [19], CPSO is represented by 30 [19], HS is represented by 31 [19], GA is represented by 32 [19], FSO is represented by 33 [19], GSA is represented by 34 [19], BSOA is represented by 35 [19], ABC is represented by 36 [19], and PSO-3P is represented by 37 .

the parameters were set as follows: $\phi_{1}=\phi_{2}=2.05$ and $\phi=\phi_{1}+\phi_{2} ;$ then,

$$
\begin{aligned}
\alpha & =\frac{2}{\phi-2+\sqrt{\phi^{2}-4 * \phi}} ; \\
\varphi_{1} & =\alpha * \phi_{1} ; \\
\varphi_{2} & =\alpha * \phi_{2} .
\end{aligned}
$$

For phase 2 and phase 3 the parameters were set as $c=3$, it $F_{1}=75$, it $F_{2}=150$, it $F_{3}=$ Max It, and prop $=0.25$.

The algorithm was implemented in Matlab R2008a and was run in an Intel Core i5-3210M processor computer at $2.5 \mathrm{GHz}$, running on Windows 8 .

4.1. Unconstrained Optimization. In this section, we present the results obtained for problems with 120 or less variables. Data reported in each of the following tables derive from 24 independent executions of the algorithm for each function. The algorithm stops when a maximum of 1500 iterations has been done or the optimum has been found. In order to get a good mean efficiency, the number of particles used for each 




Algorithm 1: PSO algorithm.

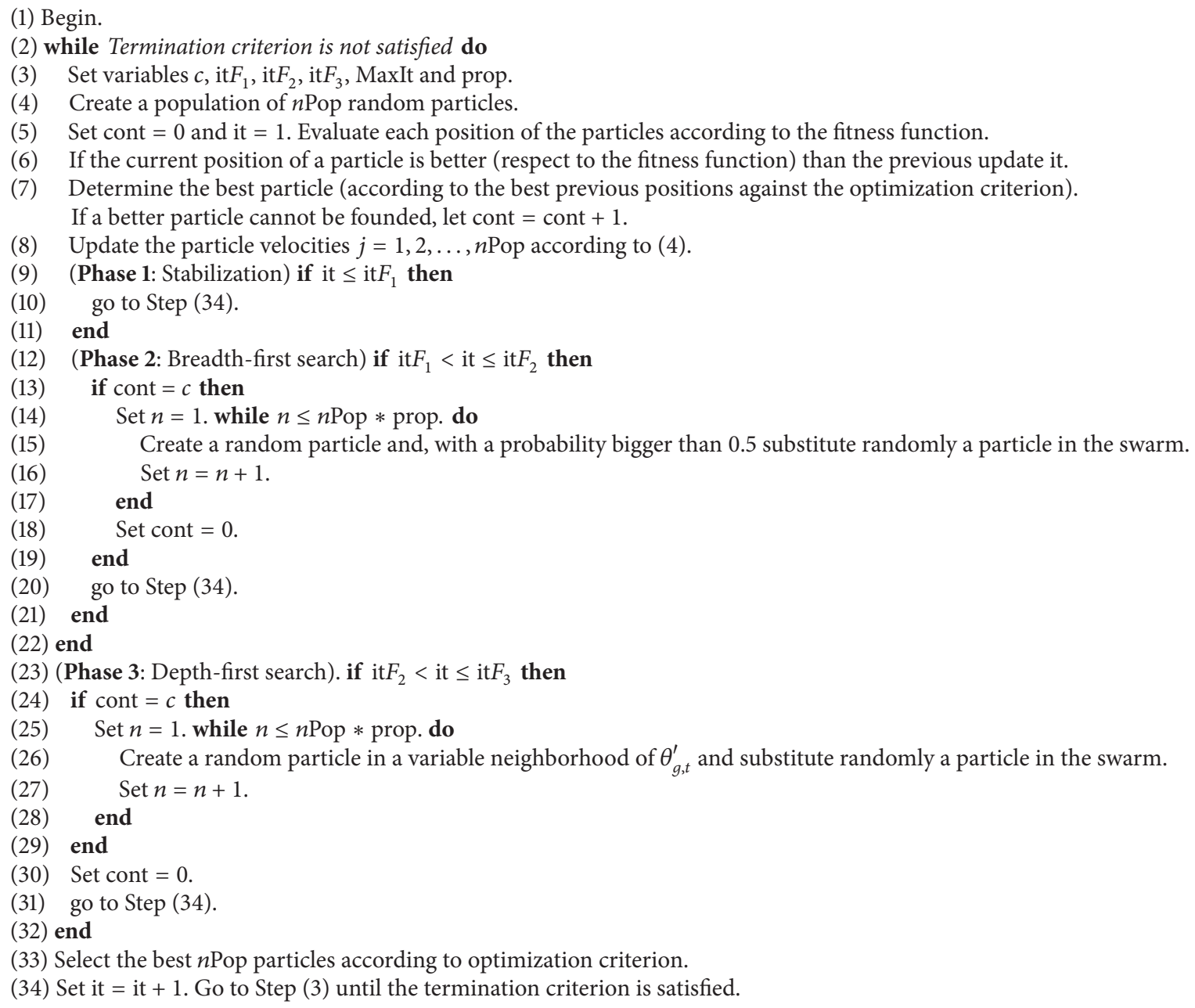

Algorithm 2: PSO-3P algorithm.

function was tuned using a brute-force approach; thus it can range between 3 and 240 particles for different problems.

Tables 1 and 2 include, for each function, the number of particles (Part.), the average efficiency (Mean Eff.) using (5), the average time per run in seconds (Time (sec)), and the average number of iterations per run (Mean Iter.).
The performance of the PSO-3P is remarkable for $\mathrm{DeV}$ illiersGlasser02, Damavandi, and CrossLegTable functions, where the success rate was superior to those reported in [18].

4.2. Experiments Using Few Particles. As an additional study on the behavior of the proposed PSO-3P, results obtained 
TABLE 6: Griewank problem.

\begin{tabular}{|c|c|c|c|c|c|c|c|c|}
\hline Algorithm & Dim. & M. G/I & $\mathrm{P}$. & EOF & Best & Average & Median & Time (s) \\
\hline PSO-3P & 10 & 500 & 3 & $282^{*}$ & 0 & 0 & 0 & 0.338 \\
\hline PSO-3P & 30 & 500 & 3 & $513^{*}$ & 0 & $1.61 E-05$ & 0 & 0.86 \\
\hline ELIPSO [19] & 30 & 100 & 1500 & - & $1.63 E-04$ & $2.27 E-04$ & $2.55 E-04$ & - \\
\hline LDWIPSO [19] & 30 & 100 & 1500 & - & 0.0002 & 0.0135 & 0.0089 & - \\
\hline FIWPSO [19] & 30 & 100 & 1500 & - & 0.0007 & 0.0118 & 0.0097 & - \\
\hline CIWPSO [19] & 30 & 100 & 1500 & - & 0.0015 & 0.0124 & 0.0119 & - \\
\hline RIWPSO [19] & 30 & 100 & 1500 & - & 0 & 0.0114 & 0.0083 & - \\
\hline TVACPSO [19] & 30 & 100 & 1500 & - & 0 & 0.0209 & 0.0148 & - \\
\hline COPSO [19] & 30 & 100 & 1500 & - & 0 & 0.0136 & 0.0136 & - \\
\hline IRPEO [13] & 30 & 50000 & 50 & - & $1.04 E-05$ & $1.92 E-05$ & - & - \\
\hline pPSA [20] & 30 & 2000 & 30 & - & $3.12 E-07$ & $1.21 E-02$ & $9.86 E-03$ & - \\
\hline PSO [21] & 30 & 100 & - & 170000 & - & 0 & - & 0.52 \\
\hline SFLA [21] & 30 & 100 & - & 120000 & - & $1.00 E-02$ & - & 0.45 \\
\hline MSFLA [21] & 30 & 100 & - & 70000 & - & 0 & - & 0.28 \\
\hline MSFLA-EO [21] & 30 & 100 & - & 50000 & - & 0 & - & 0.21 \\
\hline PSO-EO [22] & 30 & 20000 & 30 & - & 0 & 0 & - & 0.23 \\
\hline LX-PM [23] & 30 & 5000 & 300 & 100001 & - & $1.94 E-03$ & - & 1.851 \\
\hline LX-MPTM [23] & 30 & 5000 & 300 & 143371 & - & $1.14 E-03$ & - & 2.723 \\
\hline LX-NUM [23] & 30 & 5000 & 300 & 159971 & - & $8.57 E-03$ & - & 3.035 \\
\hline HX-PM [23] & 30 & 5000 & 300 & 236391 & - & $1.94 E-03$ & - & 3.554 \\
\hline HX-MPTM [23] & 30 & 5000 & 300 & 253931 & - & $1.52 E-03$ & - & 4.486 \\
\hline HX-NUM [23] & 30 & 5000 & 300 & 252571 & - & $3.68 E-03$ & - & 4.457 \\
\hline ADM [24] & 30 & $519^{*}$ & - & - & - & $4.43 E-03$ & - & 20.47 \\
\hline $\mathrm{RM}[24]$ & 30 & $28743^{*}$ & - & - & - & $1.36 E-02$ & - & 3278.67 \\
\hline PLM [24] & 30 & $277288^{*}$ & - & - & - & $5.74 E-03$ & - & 2987.69 \\
\hline NUM [24] & 30 & $27915^{*}$ & - & - & - & $2.45 E-02$ & - & 819.56 \\
\hline MNUM [24] & 30 & $15118^{*}$ & - & - & - & $3.66 E-02$ & - & 478.1 \\
\hline PM [24] & 30 & $28864^{*}$ & - & - & - & $1.02 E+00$ & - & 900.25 \\
\hline PSO-3P & 50 & 500 & 3 & $501^{*}$ & 0 & $9.54 E-06$ & 0 & 0.646 \\
\hline PSO [21] & 50 & 100 & - & 1300000 & - & 0 & - & 4.32 \\
\hline SFLA [21] & 50 & 100 & - & 3400000 & - & $1.00 E-02$ & - & 11.98 \\
\hline MSFLA [21] & 50 & 100 & - & 460000 & - & 0 & - & 1.91 \\
\hline MSFLA-EO [21] & 50 & 100 & - & 820000 & - & 0 & - & 2.06 \\
\hline CSA [25] & 50 & 2000 & - & 4000 & - & $1.01 E+00$ & - & - \\
\hline ACSA [25] & 50 & 2000 & - & 2500 & - & $7.00 E-01$ & - & - \\
\hline PSO-3P & 100 & 500 & 3 & $485^{*}$ & 0 & $1.44 E-06$ & 0 & 0.589 \\
\hline ELPSO [19] & 100 & 100 & 5000 & - & 0.1846 & 0.2612 & 0.2127 & - \\
\hline CPSO [19] & 100 & - & - & - & 0.2347 & 0.2841 & 0.2793 & - \\
\hline HS [19] & 100 & - & - & - & 244.5269 & 271.336 & 268.3095 & - \\
\hline GA [19] & 100 & - & - & - & 86.0552 & 104.867 & 108.7177 & - \\
\hline FSO [19] & 100 & - & - & - & 0.0136 & 0.0152 & 0.0151 & - \\
\hline GSA [19] & 100 & - & - & - & 0.2126 & 1.1321 & 0.6543 & - \\
\hline BSOA [19] & 100 & - & - & - & 60.9781 & 83.5311 & 84.5294 & - \\
\hline $\mathrm{ABC}$ [19] & 100 & - & - & - & 722.3432 & 817.3863 & 844.5736 & - \\
\hline PSO-3P & 120 & 500 & 3 & $498^{*}$ & 0 & $1.44 E-07$ & 0 & 0.624 \\
\hline PSO-3P & 1000 & 500 & 3 & $507^{*}$ & 0 & $1.18 E-04$ & 0 & 0.617 \\
\hline
\end{tabular}

* Average. 
TABLE 7: Rastrigin problem.

\begin{tabular}{|c|c|c|c|c|c|c|c|c|}
\hline Algorithm & Dim. & M. G/I & P. & EOF & Best & Average & Median & Time (s) \\
\hline PSO-3P & 10 & 500 & 3 & $878^{*}$ & 0 & $4.72 E-02$ & 0 & 1.101 \\
\hline PSO-3P & 30 & 500 & 3 & $510^{*}$ & 0 & $3.21 E-07$ & 0 & 0.584 \\
\hline ELIPSO [19] & 30 & 100 & 1500 & - & 3.8941 & 8.6403 & 8.8185 & - \\
\hline LDWIPSO [19] & 30 & 100 & 1500 & - & 13.9294 & 25.67 & 26.8639 & - \\
\hline FIWPSO [19] & 30 & 100 & 1500 & - & 22.8841 & 29.5503 & 28.3564 & - \\
\hline CIWPSO [19] & 30 & 100 & 1500 & - & 7.9597 & 19.0042 & 19.8992 & - \\
\hline RIWPSO [19] & 30 & 100 & 1500 & - & 11.9397 & 25.5707 & 25.3715 & - \\
\hline TVACPSO [19] & 30 & 100 & 1500 & - & 9.9496 & 24.7745 & 25.3714 & - \\
\hline COPSO [19] & 30 & 100 & 1500 & - & 30.8437 & 51.687 & 47.758 & - \\
\hline IRPEO [13] & 30 & 50000 & 50 & - & $2.47 E-05$ & $6.19 E-05$ & - & - \\
\hline pPSA [20] & 30 & 2000 & 30 & - & $4.78 E+01$ & $8.11 E+01$ & $8.21 E+01$ & - \\
\hline PSO-EO [22] & 30 & 20000 & 10 & - & 0 & $0.00 E+00$ & - & 0.61 \\
\hline LX-PM [23] & 30 & 5000 & 300 & 165471 & - & $0.00 E+00$ & - & 2.997 \\
\hline LX-MPTM [23] & 30 & 5000 & 300 & 350541 & - & $1.23 E-12$ & - & 6.515 \\
\hline LX-NUM [23] & 30 & 5000 & 300 & - & - & $7.30 E+00$ & - & - \\
\hline HX-PM [23] & 30 & 5000 & 300 & 167851 & - & $0.00 E+00$ & - & 2.441 \\
\hline HX-MPTM [23] & 30 & 5000 & 300 & 245281 & - & $9.22 E-12$ & - & 4.219 \\
\hline HX-NUM [23] & 30 & 5000 & 300 & 426651 & - & $3.11 E-13$ & - & 7.358 \\
\hline $\mathrm{ADM}[24]$ & 30 & $1456^{*}$ & - & - & - & $1.36 E+01$ & - & 57.03 \\
\hline $\mathrm{RM}[24]$ & 30 & $12978^{*}$ & - & - & - & $1.30 E-02$ & - & 1638.42 \\
\hline PLM [24] & 30 & $10467^{*}$ & - & - & - & $4.31 E-03$ & - & 971.72 \\
\hline NUM [24] & 30 & $16410^{*}$ & - & - & - & $4.43 E-02$ & - & 516.03 \\
\hline MNUM [24] & 30 & $6468^{*}$ & - & - & - & $1.80 E+01$ & - & 214.95 \\
\hline PM [24] & 30 & $20712^{*}$ & - & - & - & $8.23 E+00$ & - & 709.02 \\
\hline PSO-3P & 50 & 500 & 3 & $413^{*}$ & 0 & $1.63 E-07$ & 0 & 0.482 \\
\hline PSO [21] & 50 & 10000 & - & - & - & $3.14 E+01$ & - & - \\
\hline SFLA [21] & 50 & 10000 & - & - & - & $5.96 E+00$ & - & - \\
\hline MSFLA [21] & 50 & 10000 & - & 10000000 & - & $2.00 E-03$ & - & 19.72 \\
\hline MSFLA-EO [21] & 50 & 10000 & - & 4600000 & - & $0.00 E+00$ & - & 9.41 \\
\hline CSA [25] & 50 & 2000 & - & 4000 & - & $9.72 E-07$ & - & - \\
\hline ACSA [25] & 50 & 2000 & - & 2500 & - & $8.56 E-09$ & - & - \\
\hline PSO-3P & 100 & 500 & 3 & $510^{*}$ & 0 & $8.48 E-05$ & 0 & 0.595 \\
\hline ELPSO [19] & 100 & 100 & 5000 & - & 1.0448 & 5.5402 & 5.7829 & - \\
\hline CPSO [19] & 100 & - & - & - & 49.8618 & 78.782 & 82.187 & - \\
\hline HS [19] & 100 & - & - & - & 300.2257 & 415.5759 & 360.5646 & - \\
\hline GA [19] & 100 & - & - & - & 720.2649 & 768.2887 & 775.294 & - \\
\hline FSO [19] & 100 & - & - & - & 169.1787 & 214.1549 & 218.9371 & - \\
\hline GSA [19] & 100 & - & - & - & 27.8589 & 29.8488 & 29.8488 & - \\
\hline BSOA [19] & 100 & - & - & - & 135.4258 & 164.6546 & 146.3873 & - \\
\hline $\mathrm{ABC}[19]$ & 100 & - & - & - & 735.1485 & 753.3054 & 756.6776 & - \\
\hline PSO-3P & 120 & 500 & 3 & $466^{*}$ & 0 & $9.16 E-06$ & 0 & 0.372 \\
\hline PSO-3P & 1000 & 500 & 3 & $516^{*}$ & 0 & $1.28 E-04$ & 0 & 0.4 \\
\hline
\end{tabular}

*Average.

with small populations are investigated in this section. Indeed, for some instances, the global optimum was found using only 3 or 6 particles and, in average, less than 3000 evaluations of the objective function.

In this case, the algorithm was executed 24 times, and it stops when a maximum of 3000 iterations per run has been done or when the optimum has been found. Tables 3 and 4 include the functions that were solved to optimality, at least in one run among the 24 . These tables show the name of the function in column 2. The number of particles used for each case is presented in column 3. Column 4 includes the average time per run in seconds. The percentage of runs in which the global optimum was obtained is included in column 5. The average number of iterations per run is displayed in column 
TABLE 8: Rosenbrock problem.

\begin{tabular}{|c|c|c|c|c|c|c|c|c|}
\hline Algorithm & Dim. & M. G/I & P. & EOF & Best & Average & Median & Time (s) \\
\hline PSO-3P & 10 & 500 & 3 & $587^{*}$ & 0 & $3.71 E-01$ & 0 & 0.69 \\
\hline PSO-3P & 30 & 500 & 3 & $522^{*}$ & 0 & $1.22 E-02$ & 0 & 0.61 \\
\hline ELIPSO [19] & 30 & 100 & 1500 & - & 1.1337 & 5.8172 & 5.8938 & - \\
\hline LDWIPSO [19] & 30 & 100 & 1500 & - & 4.4676 & 52.7099 & 29.2173 & - \\
\hline FIWPSO [19] & 30 & 100 & 1500 & - & 26.9238 & 52.5216 & 49.8166 & - \\
\hline CIWPSO [19] & 30 & 100 & 1500 & - & 0.0186 & 8.6884 & 0.561 & - \\
\hline RIWPSO [19] & 30 & 100 & 1500 & - & 0.2243 & 28.3862 & 24.8883 & - \\
\hline TVACPSO [19] & 30 & 100 & 1500 & - & $2.40 E-03$ & $3.93 E+01$ & $2.73 E+01$ & - \\
\hline COPSO [19] & 30 & 100 & 1500 & - & $1.28 E+00$ & $4.55 E+01$ & 45.7893 & - \\
\hline pPSA [20] & 30 & 2000 & 30 & - & $1.43 E+01$ & $6.37 E+01$ & $2.65 E+01$ & - \\
\hline IRPEO [13] & 30 & 50000 & 50 & - & $5.36 E-02$ & $8.64 E-01$ & - & - \\
\hline PSO-EO [22] & 30 & 100000 & 30 & - & $9.50 E-04$ & $9.88 E-04$ & - & 117.1 \\
\hline LX-PM [23] & 30 & 5000 & 300 & - & - & $1.58 E+01$ & - & - \\
\hline LX-MPTM [23] & 30 & 5000 & 300 & - & - & $1.85 E+01$ & - & - \\
\hline X-NUM [23] & 30 & 5000 & 300 & - & - & $1.85 E+01$ & - & - \\
\hline HX-PM [23] & 30 & 5000 & 300 & 669751 & - & $1.84 E+01$ & - & 5.453 \\
\hline HX-MPTM [23] & 30 & 5000 & 300 & - & - & $1.61 E+01$ & - & - \\
\hline HX-NUM [23] & 30 & 5000 & 300 & 1368691 & - & $1.25 E+01$ & - & 14.621 \\
\hline ADM [24] & 30 & $30000^{*}$ & - & - & - & $6.58 E+00$ & - & 41.46 \\
\hline $\mathrm{RM}[24]$ & 30 & $29863^{*}$ & - & - & - & $6.98 E+01$ & - & 1491.56 \\
\hline PLM [24] & 30 & $29625^{*}$ & - & - & - & $5.13 E+01$ & - & 647.87 \\
\hline NUM [24] & 30 & $30000^{*}$ & - & - & - & $6.67 E+01$ & - & 379.56 \\
\hline MNUM [24] & 30 & $30000^{*}$ & - & - & - & $4.03 E+00$ & - & 173.61 \\
\hline PM [24] & 30 & $30000^{*}$ & - & - & - & $4.04 E+03$ & - & 404.41 \\
\hline PSO-3P & 40 & 40 & 3 & $953^{*}$ & 0 & $1.91 E-01$ & $0.00 E+00$ & 1.1 \\
\hline PSO [21] & 40 & 20000 & - & - & - & $4.02 E+01$ & - & - \\
\hline SFLA [21] & 40 & 20000 & - & - & - & $5.28 E+00$ & - & - \\
\hline MSFLA [21] & 40 & 20000 & - & - & - & $4.00 E-03$ & - & - \\
\hline MSFLA-EO [21] & 40 & 20000 & - & 53000000 & - & $2.00 E-03$ & - & 359 \\
\hline PSO-3P & 50 & 500 & 3 & $565^{*}$ & 0 & $2.02 E+00$ & 0 & 0.604 \\
\hline CSA [25] & 50 & 2000 & - & 4000 & - & $2.94 E+00$ & - & - \\
\hline ACSA [25] & 50 & 2000 & - & 2500 & - & $1.75 E+00$ & - & - \\
\hline PSO-3P & 100 & 500 & 3 & $553^{*}$ & 0 & $4.09 E+00$ & $0.00 E+00$ & 0.65 \\
\hline ELPSO [19] & 100 & 100 & 5000 & - & 3.7441 & 8.739 & 8.3733 & - \\
\hline CPSO [19] & 100 & - & - & - & 70.9597 & 209.9321 & 225.3372 & - \\
\hline HS [19] & 100 & - & - & - & $2.94 E+05$ & $3.19 E+05$ & $3.17 E+05$ & - \\
\hline GA [19] & 100 & - & - & - & $2.13 E+04$ & $2.61 E+04$ & $2.58 E+04$ & - \\
\hline FSO [19] & 100 & - & - & - & 96.4872 & 97.8001 & 97.7481 & - \\
\hline GSA [19] & 100 & - & - & - & 93.0005 & 93.0768 & 93.0122 & - \\
\hline BSOA [19] & 100 & - & - & - & 156.385 & 206.5988 & 215.7586 & - \\
\hline $\mathrm{ABC}[19]$ & 100 & - & - & - & $1.25 E+06$ & $1.38 E+06$ & $1.28 E+06$ & - \\
\hline PSO-3P & 120 & 500 & 3 & $599^{*}$ & 0 & $4.91 E+00$ & 0 & 0.69 \\
\hline PSO-3P & 1000 & 750 & 3 & $1948^{*}$ & 0 & $3.57 E-01$ & $2.14 E-02$ & 2.576 \\
\hline
\end{tabular}

${ }^{*}$ Average.

6. Finally, the number of evaluations of the objective function, EOF, is presented in column 7.

Even for this case, when the algorithm was restricted to use few particles and iterations, the success rate was satisfactory for DeVilliersGlasser02 and CrossLegTable functions. It is worth remembering that the number of particles, or iterations, reported in Table 1 is higher, since the data presented in the previous section was generated after tuning the parameters of the algorithm for each function, in order to increase its efficiency.

4.3. High Dimensional Problems. Finally, results obtained for some scalable functions are presented in this section, in 
TABLE 9: Sphere problem.

\begin{tabular}{|c|c|c|c|c|c|c|c|c|}
\hline Algorithm & Dim. & M. G/I & P. & EOF & Best & Average & Median & Time (s) \\
\hline PSO-3P & 10 & 500 & 3 & $483^{*}$ & 0 & $4.75 E-08$ & 0 & 0.569 \\
\hline PSO-3P & 30 & 500 & 3 & $489^{*}$ & 0 & $1.51 E-08$ & 0 & 0.56 \\
\hline ELIPSO [19] & 30 & 100 & 1500 & - & $2.979 E-08$ & $5.244 E-08$ & $5.170 E-06$ & - \\
\hline LDWIPSO [19] & 30 & 100 & 1500 & - & $1.360 E-08$ & $6.110 E-08$ & $5.920 E-08$ & - \\
\hline FIWPSO [19] & 30 & 100 & 1500 & - & $7.280 E-08$ & $1.701 E-07$ & $1.173 E-07$ & - \\
\hline CIWPSO [19] & 30 & 100 & 1500 & - & $5.400 E-08$ & $1.565 E-07$ & $1.670 E-07$ & - \\
\hline RIWPSO [19] & 30 & 100 & 1500 & - & $1.600 E-08$ & $4.810 E-07$ & $6.900 E-08$ & - \\
\hline TVACPSO [19] & 30 & 100 & 1500 & - & $4.430 E-10$ & $1.077 E-09$ & $1.046 E-09$ & - \\
\hline COPSO [19] & 30 & 100 & 1500 & - & $5.080 E-09$ & $9.550 E-09$ & $9.470 E-09$ & - \\
\hline IRPEO [13] & 30 & 50000 & 50 & - & $1.88 E-01$ & $2.96 E-01$ & - & - \\
\hline pPSA [20] & 30 & 2000 & 30 & - & $5.60 E-06$ & $7.88 E-06$ & $7.93 E-06$ & - \\
\hline PSO-EO [22] & 30 & 20000 & 10 & - & 0 & $0.00 E+00$ & - & 0.61 \\
\hline LX-PM [23] & 30 & 5000 & 300 & 43541 & - & $4.75 E-11$ & - & 0.505 \\
\hline LX-MPTM [23] & 30 & 5000 & 300 & 59861 & - & $1.32 E-07$ & - & 0.724 \\
\hline LX-NUM [23] & 30 & 5000 & 300 & 67661 & - & $3.34 E-11$ & - & 0.819 \\
\hline HX-PM [23] & 30 & 5000 & 300 & 89751 & - & $4.75 E-11$ & - & 0.733 \\
\hline HX-MPTM [23] & 30 & 5000 & 300 & 87031 & - & $5.48 E-05$ & - & 0.944 \\
\hline HX-NUM [23] & 30 & 5000 & 300 & 107581 & - & $3.64 E-04$ & - & 1.165 \\
\hline $\mathrm{ADM}[24]$ & 30 & $285^{*}$ & - & - & - & 0 & - & 11.45 \\
\hline RM [24] & 30 & $29500^{*}$ & - & - & - & $3.31 E-06$ & - & 2577.08 \\
\hline PLM [24] & 30 & $29678^{*}$ & - & - & - & $5.62 E-07$ & - & 2538.16 \\
\hline NUM [24] & 30 & $29788^{*}$ & - & - & - & $1.13 E-06$ & - & 899.87 \\
\hline MNUM [24] & 30 & $11585^{*}$ & - & - & - & $0.00 E+00$ & - & 336.02 \\
\hline PM [24] & 30 & $28498^{*}$ & - & - & - & $1.20 E-02$ & - & 994.49 \\
\hline PSO-3P & 50 & 500 & 3 & $469^{*}$ & 0 & $3.03 E-08$ & 0 & 0.539 \\
\hline PSO-3P & 100 & 500 & 3 & $481^{*}$ & 0 & $1.27 E-07$ & 0 & 0.569 \\
\hline ELPSO [19] & 100 & 100 & 5000 & - & $4.297 E-05$ & $6.035 E-05$ & $5.811 E-05$ & - \\
\hline CPSO [19] & 100 & - & - & - & $2.708 E-04$ & $5.398 E-04$ & $4.095 E-04$ & - \\
\hline HS [19] & 100 & - & - & - & 69.0111 & 76.0844 & 78.0859 & - \\
\hline GA [19] & 100 & - & - & - & 23.7734 & 29.4081 & 31.2806 & - \\
\hline FSO [19] & 100 & - & - & - & $2.001 E-04$ & $2.211 E-04$ & $2.216 E-04$ & - \\
\hline GSA [19] & 100 & - & - & - & 0.0562 & 0.0672 & 0.0691 & - \\
\hline BSOA [19] & 100 & - & - & - & 0.3406 & 0.3696 & 0.3720 & - \\
\hline $\mathrm{ABC}$ [19] & 100 & - & - & - & 198.6946 & 230.8250 & 237.4058 & - \\
\hline PSO-3P & 120 & 500 & 3 & $418^{*}$ & 0 & $1.39 E-08$ & 0 & 0.492 \\
\hline PSO-3P & 1000 & 500 & 3 & $486^{*}$ & 0 & $3.64 E-08$ & 0 & 0.599 \\
\hline
\end{tabular}

${ }^{*}$ Average.

order to investigate the performance of PSO-3P on highdimensional problems. The test functions used in this framework are Ackley, Griewank, Rastrigin, Rosenbrock, Sphere, and Zakharov. The experiments include dimensions 10, 30, $50,100,120$, and 1000 . Results reported by other authors, as far as we know, only include up to 100 dimensions.

Tables 5-10 highlight the results of PSO-3P and different algorithms for these functions. The name of the algorithm is included in the first column; the second column shows the dimension of the problem (Dim.). The number of generations (G), or iterations (I), is incorporated in column three. The fourth column includes the number of particles; the number of evaluations of the objective (EOF), or fitness, function is presented in column five. The sixth column shows the best value found by the algorithm; the average and median value are presented in columns seven and eight, respectively; finally, the last column includes the running time in seconds. We must remark that not all this information was reported in the reviewed literature; thus some cells remain empty.

For Ackley's function, see Table 5; the PSO-3P always found solutions very close to the global optimum; besides the median was very close to the global optimum for all dimensions (10,30,50,100,120, and 1000). Additionally, for the Ackley function with 30 dimensions, PSO-3P required less than $50 \%$ of the number of evaluations of the objective function compared to the other algorithms. 
TABLE 10: Zakharov problem.

\begin{tabular}{|c|c|c|c|c|c|c|c|c|}
\hline Algorithm & Dim. & M. G/I & P. & EOF & Best & Average & Median & Time (s) \\
\hline PSO-3P & 10 & 500 & 3 & $507^{*}$ & 0 & $2.33 E-05$ & 0 & 0.603 \\
\hline PSO-3P & 30 & 500 & 3 & $542^{*}$ & 0 & $8.79 E-05$ & 0 & 0.643 \\
\hline ELIPSO [19] & 30 & 100 & 1500 & - & 0.0001 & 0.0003 & 0.0002 & - \\
\hline LDWIPSO [19] & 30 & 100 & 1500 & - & 0.0001 & 0.0005 & 0.0004 & - \\
\hline FIWPSO [19] & 30 & 100 & 1500 & - & 0.0008 & 0.0032 & 0.0028 & - \\
\hline CIWPSO [19] & 30 & 100 & 1500 & - & 0.001 & 0.003 & 0.0021 & - \\
\hline RIWPSO [19] & 30 & 100 & 1500 & - & 0.0003 & 0.0019 & 0.0012 & - \\
\hline TVACPSO [19] & 30 & 100 & 1500 & - & $4.95 E-05$ & $1.36 E-04$ & $1.37 E-04$ & - \\
\hline COPSO [19] & 30 & 100 & 1500 & - & 0.0524 & 6.9459 & 2.1362 & - \\
\hline IRPEO [13] & 30 & 50000 & 50 & - & $1.88 E-01$ & $5.59 E-01$ & - & - \\
\hline LX-PM [23] & 30 & 5000 & 300 & 63271 & - & $1.95 E-20$ & - & 1.563 \\
\hline LX-MPTM [23] & 30 & 5000 & 300 & 65711 & - & $8.04 E-15$ & - & 1.642 \\
\hline LX-NUM [23] & 30 & 5000 & 300 & 78681 & - & $3.32 E-10$ & - & 1.969 \\
\hline HX-PM [23] & 30 & 5000 & 300 & 92891 & - & $1.95 E-20$ & - & 1.959 \\
\hline HX-MPTM [23] & 30 & 5000 & 300 & 94701 & - & $7.86 E-09$ & - & 2.243 \\
\hline HX-NUM [23] & 30 & 5000 & 300 & 210791 & - & $2.86 E-01$ & - & 5.06 \\
\hline $\mathrm{ADM}[24]$ & 30 & $1769^{*}$ & - & - & - & 0 & - & 70.38 \\
\hline RM [24] & 30 & $14286^{*}$ & - & - & - & $4.05 E+00$ & - & 1249.5 \\
\hline PLM [24] & 30 & $15252^{*}$ & - & - & - & $3.08 E-05$ & - & 1306.32 \\
\hline NUM [24] & 30 & $6536^{*}$ & - & - & - & $4.88 E+01$ & - & 239.33 \\
\hline MNUM [24] & 30 & $27744^{*}$ & - & - & - & 0 & - & 687.27 \\
\hline PM [24] & 30 & $5454^{*}$ & - & - & - & $7.09 E+01$ & - & 203.16 \\
\hline PSO-3P & 50 & 500 & 3 & $649^{*}$ & 0 & $2.11 E-05$ & 0 & 0.783 \\
\hline PSO-3P & 100 & 500 & 3 & $814^{*}$ & 0 & $8.14 E-02$ & 0 & 0.944 \\
\hline ELPSO [19] & 100 & 100 & 5000 & - & 0.2268 & 2.5016 & 2.2814 & - \\
\hline CPSO [19] & 100 & - & - & - & 17.7263 & 40.9341 & 39.9646 & - \\
\hline HS [19] & 100 & - & - & - & 287.5234 & 2694.91 & 488.3287 & - \\
\hline GA [19] & 100 & - & - & - & 369.4271 & 412.8078 & 382.7739 & - \\
\hline FSO [19] & 100 & - & - & - & 62.8325 & 74.4212 & 75.6089 & - \\
\hline GSA [19] & 100 & - & - & - & 167.7459 & 171.3504 & 168.1632 & - \\
\hline BSOA [19] & 100 & - & - & - & 91.0035 & 53.6407 & 130.7713 & - \\
\hline $\mathrm{ABC}$ [19] & 100 & - & - & - & 1052.2 & 1278.7 & 1337.6 & - \\
\hline PSO-3P & 120 & 500 & 3 & $768^{*}$ & 0 & $2.22 E-02$ & 0 & 0.932 \\
\hline PSO-3P & 1000 & 500 & 3 & $1080^{*}$ & 0 & $9.66 E+07$ & 0 & 1.268 \\
\hline
\end{tabular}

For the Griewank, Rastrigin, Rosenbrock, Sphere, and Zakharov functions, see Tables 6-10; the PSO-3P always found the global optimum in at least one run, and the median always was the global optimum for all dimensions (10, 30, 50, 100,120 , and 1000).

Special attention should be given to the number of iterations and evaluations of the objective, fitness, and function. In average, the PSO-3P required 609 evaluations of the objective function to achieve the global optimum for dimensions $10,30,50,100,120$, and 1000 and less than 0.74 seconds.

The normalized solutions for 17 instances are shown in Table 11; in this table values range between 0 and 1 . If an algorithm found a solution close to the best reported value, it is associated with 0 . On the other hand, if the best solution found by an algorithm is close to the worst reported value, it is associate with 1 . Based on Table 11, we observe that PSO-3P found the best results in $94 \%$ of the instances and only in $6 \%$ get the second best result. Also, PSO-3P is a competitive alternative to solve Ackley, Griewank, Rastrigin, Rosenbrock, Sphere, and Zakharov problems.

Results of the Wilcoxon rank sum test are shown in Figure 3; in this case, a dark square means that the algorithms are statically similar, while a clear square means the opposite. Results of the Wilcoxon rank sum test 3 show that PSO-3P is a metaheuristic similar to PSO-EO [22], LX-PM [23], HXPM [23], and ACSA [25]. On the other hand, our method is different from the remaining methods. However, PSO-3P required less number of evaluations of the objective function than its counterparts for getting good results. $P$ values involved in the Wilcoxon rank sum test are shown in the Figure 4. 


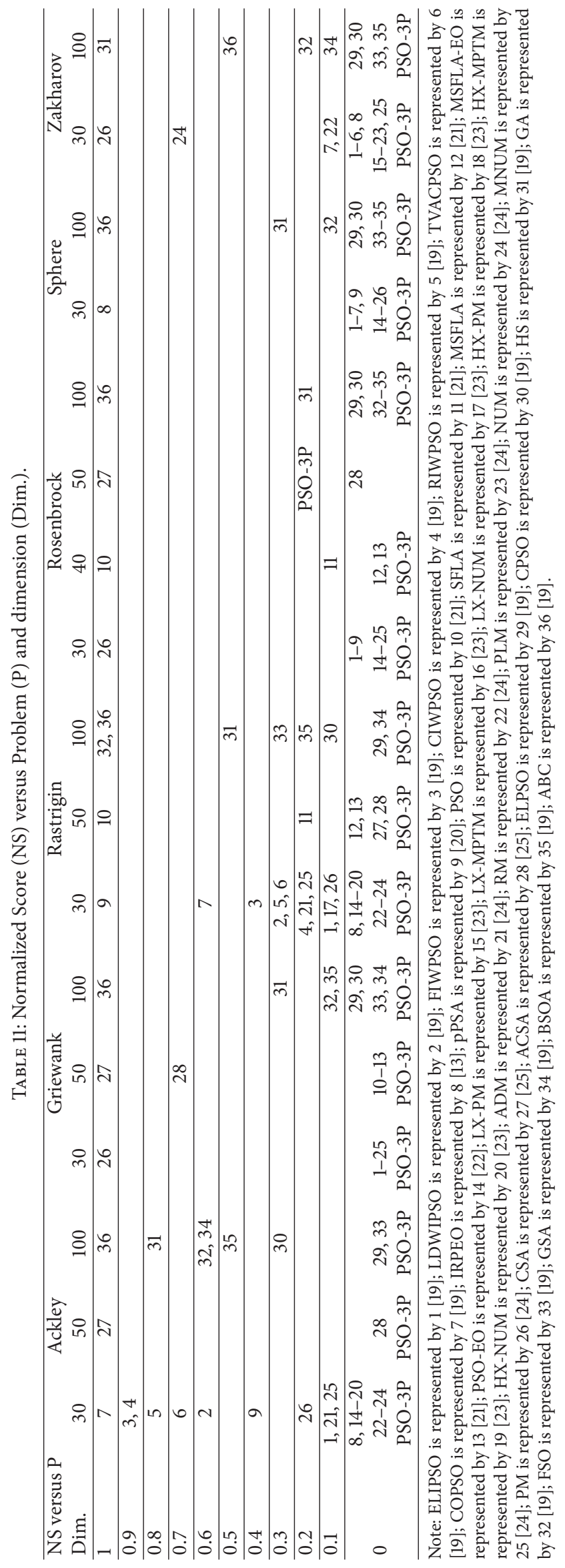




\section{Conclusions and Further Research}

In this work, a novel PSO based algorithm is with three phases: (1) stabilization, (2) breadth-first search, and (3) depth-first search. The resulting PSO-3P algorithm was tested over a set of single-objective unconstrained optimization benchmark instances. The empirical evidence shows that PSO-3P is very efficient.

Tables 5-10 highlight the fact that PSO-3P gives good results and competitive solutions for some difficult previously reported problems.

Moreover, for all benchmark functions considered in this work, PSO-3P converged faster and required fewer iterations than many specialized algorithms, regardless of the dimension of the function. PSO-3P used on average 609 evaluations of the objective function to converge to the global optimum, which represent on average $66 \%$ of the number of evaluations reported for these problems by other algorithms, and an average running time of 0.74 seconds for problems of dimension 10 to 1000 . As a matter of fact, some solutions are presented for problems of high dimension $(120,1000)$ that have not been reported before. Also, the numerical results of the Wilcoxon test show that the results obtained by PSO-3P are similar to those reported by IRPEO, LX-MPTM, MNUM, pPSA, LX-NUM, PSO, HX-PM, CSA, SFLA, HX-MPTM, ACSA, MSFLA, HX-NUM, PSO, MSFLA-EO, ADM, PSOEO, RM, MSFLA, LX-PM, PLM, MSFLA-EO, and NUM. However, the PSO-3P needs less than 1000 evaluations of the objective function for generating good results; in contrast, the other methods need more than 2500 evaluations.

It was observed that, in all the cases studied, PSO-3P can reach the global optimum or a solution can be very close to it, with small number of iterations, as well as the ability to jump deep valleys, for unconstrained optimization with 2 to 1,000 variables.

\section{Conflict of Interests}

The authors declare that there is no conflict of interests regarding the publication of this paper.

\section{Acknowledgments}

Sergio Gerardo de-los-Cobos-Silva would like to thank D. Sto. and P. V. Gpe. for their inspiration, and his family Ma, Ser, Mon, Chema, and his Flaquita for all their support.

\section{References}

[1] F. Glover, “Tabu Search, part I," ORSA Journal on Computing, vol. 1, no. 3, pp. 190-206, 1989.

[2] S. Kirkpatrick, C. D. Gelatt Jr., and M. P. Vecchi, "Optimization by simulated annealing," Science, vol. 220, no. 4598, pp. 671-680, 1983.

[3] J. H. Holland, Adaptation in Natural and Artificial Systems, University of Michigan Press, Ann Arbor, Mich, USA, 1975.

[4] F. Glover, "A template for scatter search and path relinking," in Artificial Evolution, vol. 1363 of Lecture Notes in Computer Science, pp. 1-51, Springer, Berlin, Germany, 1998.
[5] J. Kennedy and R. Eberhart, "Particle swarm optimization," in Proceedings of the IEEE International Conference on Neural Networks, vol. 4, pp. 1942-1948, December 1995.

[6] D. Sedighizadeh and E. Masehian, "Particle swarm optimization methods, taxonomy and applications," International Journal of Computer Theory and Engineering, vol. 1, no. 5, pp. 486-502, 2009.

[7] I. Muhammad, H. Rathiah, and A. K. Noor Elaiza, "An overview of particle swarm optimization variants," Procedia Engineering, vol. 53, pp. 491-496, 2013.

[8] Y. Zhao, W. Zu, and H. Zeng, "A modified particle swarm optimization via particle visual modeling analysis," Computers \& Mathematics with Applications, vol. 57, no. 11-12, pp. 20222029, 2009.

[9] C.-C. Chen, "Two-layer particle swarm optimization for unconstrained optimization problems," Applied Soft Computing Journal, vol. 11, no. 1, pp. 295-304, 2011.

[10] W. F. Abd-El-Wahed, A. A. Mousa, and M. A. El-Shorbagy, "Integrating particle swarm optimization with genetic algorithms for solving nonlinear optimization problems," Journal of Computational and Applied Mathematics, vol. 235, no. 5, pp. 1446-1453, 2011.

[11] H. Kahramanh and N. Allahverdi, "Partcle swarm optimization with flexible swarm for unconstrained optimization," International Journal of Intelligent Systems and Applications in Engineering, vol. 1, no. 1, pp. 8-13, 2013.

[12] J.-Y. Wu, "Solving unconstrained global optimization problems via hybrid swarm intelligence approaches," Mathematical Problems in Engineering, vol. 2013, Article ID 256180, 15 pages, 2013.

[13] G.-Q. Zeng, K.-D. Lu, J. Chen et al., "An improved realcoded population-based extremal optimization method for continuous unconstrained optimization problems," Mathematical Problems in Engineering, vol. 2014, Article ID 420652, 9 pages, 2014.

[14] S. G. De-los-Cobos-Silva, "SC-system of convergence: theory and foundations," Revista de Matemática: Teoría y Aplicaciones, vol. 22, no. 2, pp. 341-367, 2015.

[15] J. Kennedy, R. C. Eberhart, and Y. Shi, Swarm Intelligence, Morgan Kaufmann Publishers, San Diego, Calif, USA, 2001.

[16] A. R. Hedar, "Global Optimization Test Problems," 2014, http://www-optima.amp.i.kyoto-u.ac.jp/member/student/hedar/ Hedar_files/TestGO.htm.

[17] S. Surjanovic and D. Bingham, "Optimization Test Problems," 2014, http://www.sfu.ca/ ssurjano/optimization.html.

[18] A. Gavana, Global Optimization Benchmarks and AMPGO, 2014, http://infinity77.net/global_optimization/test_functions .html.

[19] A. R. Jordehi, "Enhanced leader PSO (ELPSO): a new PSO variant for solving global optimisation problems," Applied Soft Computing Journal, vol. 26, pp. 401-417, 2015.

[20] Z. Xinchao, "A perturbed particle swarm algorithm for numerical optimization," Applied Soft Computing Journal, vol. 10, no. 1, pp. 119-124, 2010.

[21] X. Li, J. Luo, M.-R. Chen, and N. Wang, "An improved shuffled frog-leaping algorithm with extremal optimisation for continuous optimisation," Information Sciences, vol. 192, pp. 143-151, 2012.

[22] M.-R. Chen, X. Li, X. Zhang, and Y.-Z. Lu, "A novel particle swarm optimizer hybridized with extremal optimization," Applied Soft Computing Journal, vol. 10, no. 2, pp. 367-373, 2010. 
[23] K. Deep and M. Thakur, "A new mutation operator for real coded genetic algorithms," Applied Mathematics and Computation, vol. 193, no. 1, pp. 211-230, 2007.

[24] P.-H. Tang and M.-H. Tseng, "Adaptive directed mutation for real-coded genetic algorithms," Applied Soft Computing Journal, vol. 13, no. 1, pp. 600-614, 2013.

[25] P. Ong, "Adaptive cuckoo search algorithm for unconstrained optimization," The Scientific World Journal, vol. 2014, Article ID 943403, 8 pages, 2014.

[26] M. Birattari, Tuning Metaheuristics: A Machine Learning Perspective, Springer, 2009. 


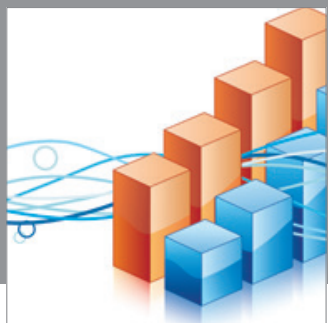

Advances in

Operations Research

mansans

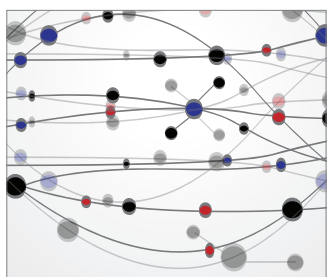

The Scientific World Journal
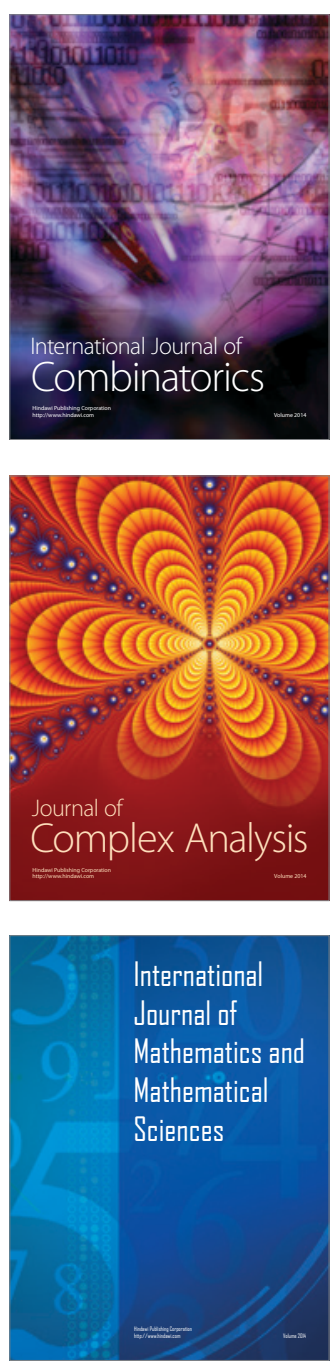
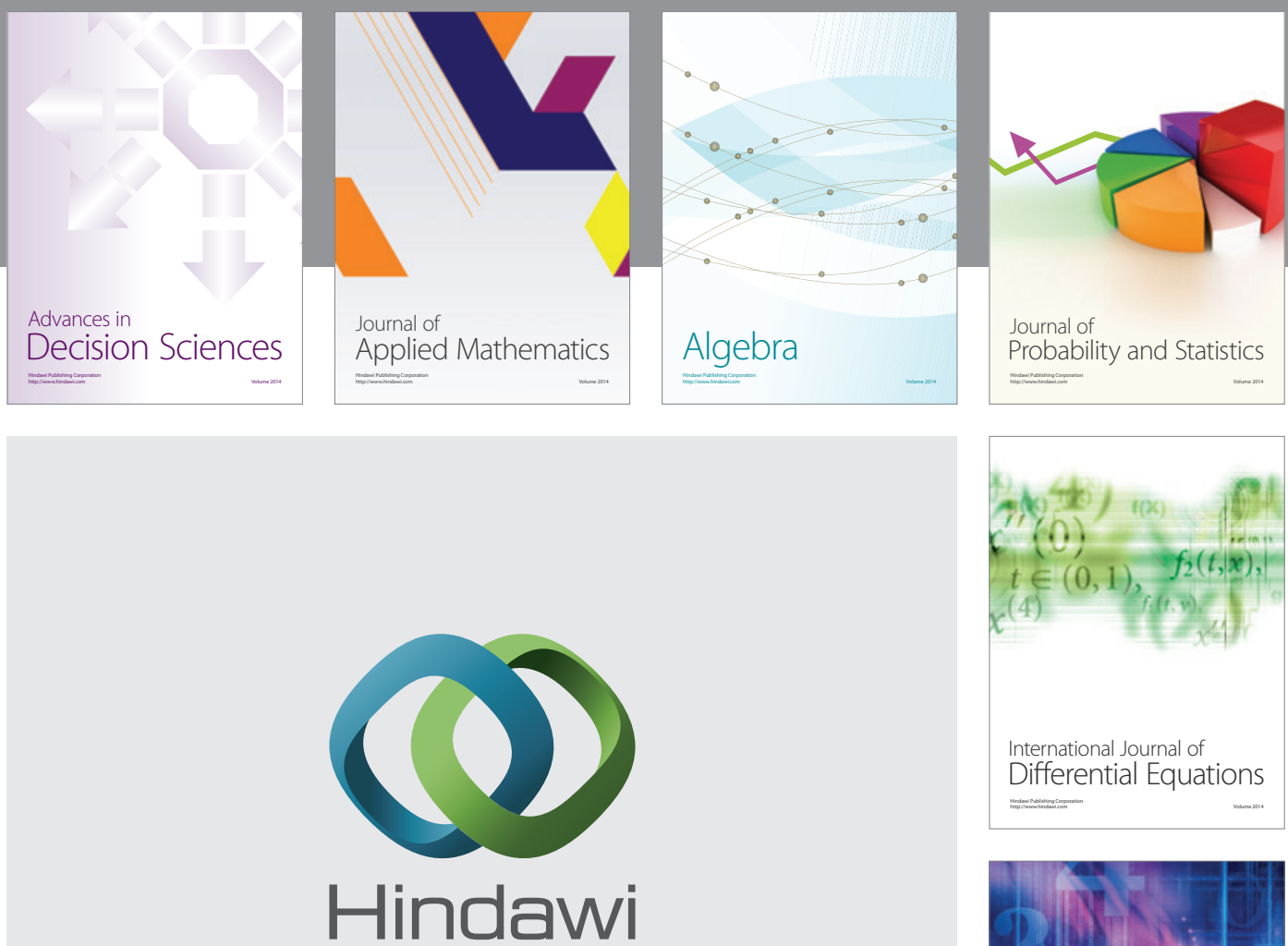

Submit your manuscripts at http://www.hindawi.com
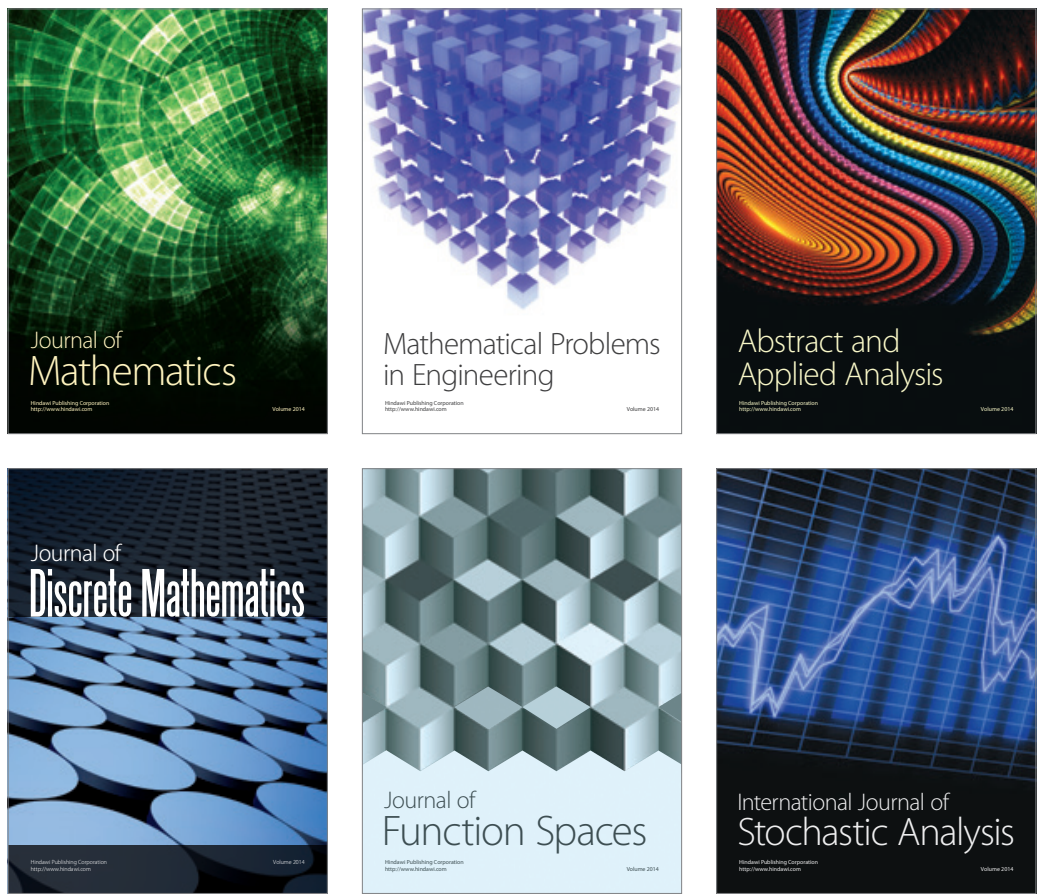

Journal of

Function Spaces




